\title{
Geleneksel Yöntemlerle Üretilen Nar Ekşisinin Antibakteriyel ve Antimutajenik Etki Potansiyeli
}

\author{
Nurcan ERBILL ${ }^{1 *}$ iD, Mehmet ARSLAN ${ }^{2}$ \\ ${ }^{1}$ Ardahan Üniversitesi, Sağllk Bilimleri Yüksekokulu, Hemşirelik Bölümü \\ ${ }^{2}$ Ardahan Üniversitesi, Sağlık Bilimleri Yüksekokulu, Sağlık Yönetimi Bölümü
}

Geliş / Received: 07/02/2019, Kabul / Accepted: 11/07/2019

\begin{abstract}
$\ddot{O} \mathbf{z}$
Nar (Punica granatum L.) günlük diyet içerisinde sıklıkla tüketilen bir meyve olup, ayrıca nar ekşisi formunda da yemek ve salatalarda çeşni olarak sıklıkla kullanılmaktadır. Bu çalışmada ise Hatay ve Şanlıurfa yörelerinde geleneksel olarak üretilen iki farklı nar ekşisi örneğinin potansiyel antibakteriyel ve antimutajenik etkisinin tespiti amaçlanmıştır. Antibakteriyel aktivite analizi agar kuyu difüzyon metoduna göre yapılmış olup, test bakterisi olarak Bacillus subtilis subsp. spizizenii ATCC 6633, Staphylococcus aureus ATCC 6538, Bacillus licheniformis ATCC 14580 ve Enterobacter aerogenes ATCC 13048 kullanılmıştır. Antimutajen etki analizlerinde ise Ames Testi kullanılmış ve Salmonella Typhimurium TA 98 ve TA 100 suşları tercih edilmişsir. Analiz sonuçlarına göre Hatay nar ekşisinin test bakterilerine karşı 18.09-25.63 mm inhibisyon zonu meydana getirdiği tespit edilirken, Şanlıurfa nar ekşisinde bu değer 14.84-22.32 mm olarak gözlemlenmiștir. Ayrıca; Ames testi sonucunda TA 98'e karşı Hatay nar ekşisinin $10 \mu \mathrm{g} \mathrm{plak}^{-1}$ ve $20 \mu \mathrm{g}$ plak ${ }^{-1}$ dozlarında, Şanlıurfa nar ekşisinin ise denenen tüm dozlarında antimutajenik etki tespit edilirken; TA 100'e karşı ise Hatay ve Şanlıurfa nar ekşisinin denenen hiçbir dozunun antimutajenik özellik göstermediği belirlenmiştir. Sonuç olarak, nar ekşisinin sahip olduğu antibakteriyel ve antimutajenik etkilerden dolayı sağlı için faydalı olduğu düşünülmekle beraber; bu sonuçların farklı bakterilerle ve nar ekşileriyle yapılan çalışmalarla desteklenmesi faydalı olacaktır.
\end{abstract}

Anahtar Kelimeler: Nar ekşisi, antibakteriyel etki, antimutajenik etki, Ames testi

Antibacterial and Antimutagenic Potential of Pomegranate Syrup Produced by Traditional Methods

\begin{abstract}
Pomegranate (Punica granatum L.) is a fruit consumed in daily-diet and pomegranate syrup obtained from pomegranate juice is used as flavouring in food and salad. In this study, it was aimed to determine the potential antibacterial and antimutagenic effects of pomegranate syrups produced traditionally in Hatay and Şanliurfa. Agar well diffusion method was used for antibacterial activity test and Bacillus subtilis subsp. spizizenii ATCC 6633, Staphylococcus aureus ATCC 6538, Bacillus licheniformis ATCC 14580, Enterobacter aerogenes ATCC 13048 were used as the test bacteria. Antimutagenic activity were tested using Ames test against TA98 and TA100 strains of Salmonella Typhimurium. Pomegranate syrup from Hatay caused inhibition zones against test bacteria as 18.09-25.63 mm, while pomegranate syrup from Şanlıurfa exhibited antibacterial activity with 14.84-22.32 mm inhibition zones. Additionally, 10 and $20 \mu$ plaque $^{-1}$ doses of pomegranate syrup from Hatay and all doses of pomegranate syrup from Şanlıurfa exhibited antimutagenic activity against TA98 strain. However, all doses of pomegranate syrup from Hatay and Şanlıurfa did not exhibit antimutagenic effect against TA100 strain. Consequently, it is considered to be beneficial for health because of its antibacterial and antimutagenic effects and it would be useful to support these results with different studies using different bacteria and pomegranade syrups.
\end{abstract}

Keywords: Pomegranate syrup, antibacterial effect, antimutagenic effect, Ames test

\section{Giriş}

Nar (Punica granatum L.) Punicaceae familyasına ait olup, ülkemizin çok soğuk kısımları hariç hemen hemen her böl-gesinde yetişebilmektedir (Özkal ve Dinç, 1993). Dünya geneline bakıldığında ise başta
Türkiye, Kıbris, Irak, İran, Suriye, ABD, İtalya, İspanya, Tunus, Fas, Afganistan, Filistin, İsrail, Misır, Suudi Arabistan, Hindistan, Çin ve Tayland olmak üzere, dünya çapında pek çok ülkede 
yetişebilmektedir (Gündoğdu ve Yılmaz, 2013).

Bilinen en eski meyve türlerinden biri olan nar, ülkemiz genelinde taze meyve olarak sıklikla tüketilmekle birlikte meyve suyu, nar pekmezi veya nar ekşisi formunda da tüketilmektedir. Nar ekşisi mutfaklarda bazı yemek-lere ve özellikle salatalara tat vermesi amacı ile siklıkla kullanılmakta olup; geleneksel olarak üretimi ülkemizde yaygın bir uygulama olmakla birlikte, son yillarda endüstriyel olarak üretilen nar ekşisi sosları da ticari olarak satılmaktadır.

Nar ve nardan elde edilen ürünlerin sağl1k açısından oldukça faydalı olduğu uzun yıllardır bilinmekte ve geçmişten günümüze halk hekimliğinde de kullanılmaktadır. Ayrıca; son yıllarda narın çeşitli bileşenleri ve aktiviteleri ile alakalı çok sayıda çalışma yapılmıştır ve yapılmaya da devam edilmektedir. Yapılan bu çalışmalardan bazıları şu şekildedir: narın yenilen kısımlarının değişen oranlarda mineral madde, şeker ve organik asit içerdiği bildirilmiştir (Ünal vd., 1995; Melgarejo vd., 2000). Turgut ve Seydim (2013) tarafindan yapılan bir çalışmada nar suyu örneklerinde birçok organik asidin bulunduğu tespit edilmiş olup, bunlar sırasıyla sitrik, malik, okzalik ve tartarik asitlerdir. Ayrıca; nar suyu içerdiği antosiyaninler, polifenolikler ve taninlerden dolayı yüksek oranda antioksidan aktiviteye sahiptir (Rahimi vd., 2012). Nar suyunun prostat kanserine karşı kanserkemopreventif ve kanser-kemoterapötik etki gösterdiği (Malik vd., 2005) ve hatta nar suyu tüketiminin AIDS hastalığının tedavisinde de önerildiği bildirilmektedir (Lee and Watson, 1998).

Önceki yıllarda narla alakalı çeşitli çalışmalar yapılmış olmakla birlikte, özellikle nar ekşisinin antimikrobiyel ve antimutajenik aktivitesi ile alakalı sınırlı sayıda çalışma mevcuttur. Konuyla alakalı yapılan çalışmalardan birinde nar ekşisinin Escherichia coli 0157 ve Listeria monocytogenes'e karşı inhibe edici etkiye sahip olduğu tespit edilmiştir (Kunduhoğlu ve Pilatin, 2009). Yapılan bir diğer çalışmada ise parça ve kıyma et örneklerinin mikroorganizma yükü nar ekşisi ile muamele edilmeden önce ve muamele edildikten sonra incelenmiştir. Elde edilen sonuçlar neticesinde mikroorganizma yükünün nar ekşisi ile muamele edilenlerde edilmeyenlere göre azaldığ1 tespit edilmiştir (Yapar, 2006). Ar1 ve Erbil (2018) tarafından yapılan farklı bir çalışmada ise ticari olarak satın alınan nar suyunun kullanılan test bakterileri üzerinde yüksek oranda antibakteriyel etki sergilediği tespit edilmiştir.

Bu çalışmada ise Şanlıurfa ve Hatay yörelerinde nar suyundan geleneksel olarak üretilen nar ekşisinin potansiyel antibakteriyel ve antimutajenik aktivitelerinin tespiti amaçlanmıştır.

\section{Materyal ve Metod}

\subsection{Nar ekşisi numunelerinin eldesi ve hazırlanması}

$\mathrm{Bu}$ çalışma esnasında kullanılan nar ekşisi numuneleri Fıstıközü Köyü/Halfeti/ Şanlıurfa ve Maşuklu Beldesi/Antakya/Hatay yörelerinde geleneksel yöntemlerle üretilmiştir. Her iki yörede de nar ekşisini üreten bireylerle görüşülmüş ve her iki yörede de aynı yöntemle üretildiği tespit edilmiştir. Her iki yörede de 2017 hasat döneminde toplanan narların kabukları ayıklanarak nar tanelerinin suyu sıkılmış ve süzülmüştür. Elde edilen nar suları koyu bir kıvam kazanana kadar kaynatılmış ve 2 gün açık havada güneşte bekletilmiştir. Böylece aynı hasat döneminde iki farklı yöreden toplanan ve aynı yöntemle üretilen nar ekşisi örnekleri kullanılmıştır. $\mathrm{Bu}$ nar ekşisi örnekleri analizler esnasında kullanılmak üzere 1:1 oranında saf su ile seyreltildikten sonra steril mikrofiltre $(0.2 \mu \mathrm{m}$ gözenek 
çaplı, Sartorius Minisart ${ }^{\circledR}$ Syringe Filter) ile sterilize edilmiş ve denemelerde kullanılmıştır. $\mathrm{Bu}$ işlem analizlerden hemen önce yapılmış ve depolamaya ihtiyaç duyulmadan kullanılmıştır.

\subsection{Antibakteriyel aktivite tayini}

Antibakteriyel aktivite tayini agar kuyu difüzyon metoduna göre yapılmış olup (Rauha vd., 2000), test bakterisi olarak Bacillus subtilis subsp. spizizenii ATCC 6633, Staphylococcus aureus ATCC 6538, Bacillus licheniformis ATCC 14580 ve Enterobacter aerogenes ATCC 13048 kullanılmıştır. Bu bakteriler günlük yaşamda sıklıkla karşılaşılan bakteriler olup, bazı durumlarda patojen etki de yaratabilmektedirler. Test bakterileri, yatık agardaki stok kültürlerden bir öze alınarak Nutrient Broth içerisine aşılanmış ve $37{ }^{\circ} \mathrm{C}$ 'de 18 saat inkübe edilmiştir. Böylece aktifleştirilen ve McFarland 0.5 'e göre ayarlanan bakteri kültürlerinin her birinden $100 \mu \mathrm{l}$ kullanılmıştır. $100 \mu \mathrm{l}$ bakteri kültürü $20 \mathrm{ml}$ steril Müller Hinton Agar içerisine aşılanmış ve homojen bir şekilde karıştırıldıktan sonra plaklar içerisine (90 mm çapında) dökülmüştür. Katılaşması için yaklaşık $30 \mathrm{dk}$ bekletilen besiyerine steril mantar delici (cork borer) yardımıyla $11 \mathrm{~mm}$ çapında oyuklar açılmış ve içerisine 150 'şer $\mu$ nar ekşisi stok çözeltilerinden eklenmiştir. Negatif kontrol olarak saf su, pozitif kontrol olarak ise Gentamisin $(10 \mu \mathrm{g} /$ disk, HIMEDIA) standart antibiyotik kullanılmıştır. Petri plakları 48 saat boyunca $37^{\circ} \mathrm{C}$ 'de inkübe edilmiştir. Çalışma üç tekrar halinde yapılmış ve zon çapları dijital kumpas yardımıyla mm olarak ölçülmüştür.

\subsection{Antimutajenik aktivite tayini}

\subsubsection{Test suşları}

Bu çalışmada antimutajen aktivite testi için $S$. Typhimurium TA 98 ve TA 100 suşları kullanılmıştır. $\mathrm{Bu}$ suşlar belirli aralıklarla $\mathrm{R}$ faktör varlığ dirençliliği, histidin ihtiyacı, kristal viyole duyarlılığ1, UVr B mutasyonu ve spontan geri dönüş oranları için Maron and Ames (1983) tarafindan tavsiye edilen metoda göre kontrol edilmiştir. Yöntemde $S$. Typhimurium TA 100 ve TA 98 suşları ile çalışılmıştır. Bu suşların seçilmesinin nedeni; TA 100 baz çifti değişimine, TA 98 ise çerçeve kaymasına yol açan mutajenlerin belirlenmesi için kullanılmaktadır. Test sonuçlarının ortalaması alınarak, kontrol grupları ile karşılaştırılmış ve değerlendirilmiştir.

\subsubsection{Antimutajenite testi}

İki farklı nar ekşisi örneğinin potansiyel antimutajenik aktivite tayini için Ames Testi kullanılmıştır (Maron and Ames, 1983). Yapılan ön denemeler sonucunda, nar ekşisi örneklerinin toksik olmadığı tespit edilen dozları $\left(10,20,40\right.$ ve $\left.80 \mu \mathrm{g}_{\text {plak }}^{-1}\right)$, S9 mix yokluğunda $S$. Typhimurium TA 98 ve TA 100'e karşı test edilmiştir. Sitotoksik olmayan dozun LD50 (bakterilerin yarısını öldüren doz)'nin üstünde olması gerekmektedir. $\mathrm{Bu}$ nedenle deneme plaklarındaki koloni sayısı kontrol plağındaki koloni sayısının yarısının altında olmaması durumunda, doz toksik olarak kabul edilmemiştir. Çalışmada kullanılan dozlar ön denemeler sonucunda bu mantikla seçilmiştir. Pozitif kontrol olarak TA 98 için $10 \mu \mathrm{g}$ plak $^{-1}$ 4-Nitro-O-fenilendiamin (4NPD; Cat. No. 10,889 8, Sigma Aldrich, St. Louis, MO, USA), TA 100 için ise $100 \mu \mathrm{g}$ plak $^{-1}$ sodyum azid (SA; Cat. No. S 2002, Sigma Aldrich) kullanılmıştır. $\mathrm{Bu}$ amaçla antimutajenik aktivite tayini için belirtilen koşullarda aktifleştirilen $S$. Typhimurium kültüründen $100 \mu$, nar ekşisi stok solüsyonu ve mutajen (4-NPD veya SA) $2 \mathrm{ml}$ top agar içerisine eklenerek karıştırılmış ve katılaşmış olan minimal glukoz agar üzerine dökülmüştür. Plaklar $37{ }^{\circ} \mathrm{C}$ 'de $48-72$ saat inkübasyona bırakılmıştır. Analizler üç 
tekrarlı olarak yapılmış ve analizler sonucunda gelişen revertant (geri dönen) koloniler dijital koloni sayım cihazı (aCOLyte 3-Synbiosis) aracılığıyla sayılmıştır.

\section{4. İstatistiksel analizler}

Antimutajenik aktivite verilerin istatistiksel değerlendirilmesi SPSS 17.0 paket istatistik programinda (SPSS Inc. Released 2008. SPSS Statistics for Windows, Version 17.0. Chicago: SPSS Inc.) yapılmıştır. Verilerin normalitesi Shapiro-Wilk testi ile kontrol edilmiştir. Normal dağılım gösteren veri setlerinin Levene testi ile homojenitesi araştırılmış ve daha sonra independentsamples $t$ testine tabi tutulmuştur. Normal dağılım göstermeyen veri setleri arasındaki farkın istatistiksel önem derecesi KruskalWallis testi uygulanarak belirlenmiştir. $(P<0.05)$. Antibakteriyel aktivite analizi neticesinde elde edilen inhibisyon zonu çaplarının standart sapmaları ve ortalama değerleri SPSS 16.0 paket programı aracılığ ile hesaplanmıştır. Veriler aritmetik ortalama \pm standart sapma şeklinde sunulmuştur.

\section{Bulgular}

Çalışmada Hatay ve Şanlıurfa yörelerinden temin edilen ve geleneksel yöntemlerle üretilmiş olan iki farklı nar ekşisi örneği kullanılmış ve potansiyel antibakteriyel ve antimutajenik aktiviteleri yönünden test edilmiştir. $\mathrm{Bu}$ amaçla, antibakteriyel aktivite agar kuyu difüzyon metoduyla test edilmiş ve sonuçlar Tablo 1'de sunulmuştur. Bulgular incelendiğinde Hatay nar ekşisinde daha fazla olmak üzere, her iki nar ekşisi örneğinde de test edilen bakterilere karş1 belirli oranda antibakteriyel aktivite gözlenmektedir. Her iki nar ekşisi örneğinin de en yüksek antibakteriyel aktiviteyi Bacillus subtilis subsp. spizizenii ATCC 6633'e karş1 gösterdiği tespit edilmiştir. $\mathrm{Bu}$ bakteriye karşı oluşan inhibisyon zonları Hatay nar ekşisinde $25.63 \mathrm{~mm}$ iken Şanlıurfa nar ekşisinde $22.32 \mathrm{~mm}$ 'dir. Hatay ve Şanlıurfa nar ekşisinin her ikisinin de en düşük inhibisyon zonunu Enterobacter aerogenes ATCC 13048'e karş1 meydana getirdiği gözlenmektedir (sırasiyla 18.09 ve $14.84 \mathrm{~mm})$.

Tablo 1. Hatay ve Şanlıurfa nar ekşilerinin antibakteriyel aktivitesi

\begin{tabular}{|c|c|c|c|}
\hline Bakteri & $\begin{array}{c}\text { Hatay nar ekşisi } \\
\text { (mm) }\end{array}$ & $\begin{array}{c}\text { Şanlıurfa nar ekşisi } \\
\text { (mm) }\end{array}$ & $\begin{array}{c}\text { Gentamisin } \\
(\mathbf{m m})\end{array}$ \\
\hline $\begin{array}{l}\text { Bacillus subtilis subsp. spizizenii } \\
\text { ATCC } 6633\end{array}$ & $25.63^{*} \pm 0.85^{* * a}$ & $22.32 \pm 0.53^{\mathrm{b}}$ & $30.70 \pm 0.43^{c}$ \\
\hline $\begin{array}{l}\text { Staphylococcus aureus ATCC } \\
6538\end{array}$ & $24.20 \pm 0.93^{\mathrm{a}}$ & $21.63 \pm 0.62^{b}$ & $19.92 \pm 0.60^{\mathrm{c}}$ \\
\hline $\begin{array}{l}\text { Bacillus licheniformis ATCC } \\
14580\end{array}$ & $23.18 \pm 0.41^{\mathrm{a}}$ & $19.72 \pm 0.41^{b}$ & $23.37 \pm 0.76^{\mathrm{a}, \mathrm{c}}$ \\
\hline $\begin{array}{l}\text { Enterobacter aerogenes ATCC } \\
13048\end{array}$ & $18.09 \pm 0.40^{\mathrm{a}}$ & $14.84 \pm 0.32^{b}$ & $20.10 \pm 0.11^{\mathrm{c}}$ \\
\hline
\end{tabular}


Ames testi gibi mutajenik yöntemler, çeşitli bileşenlerin antimutajenik ve antikarsinojenik aktivitelerinin belirlenebilmesi için kullanılmaktadır (Ikken vd., 1998). Bu çalışmada da Hatay ve Şanlıurfa'dan alınan ve geleneksel yöntemlerle elde edilen nar ekşisi numunelerinin antimutajenik aktiviteleri Maron and Ames (1983) tarafindan tavsiye edilen Ames testi ile yapılmıştır. Bunun için $S$. Typhimurium TA 98 ve TA 100 suşları kullanılmış olup, bulgular Tablo 2 ve 3 'te sunulmuştur. Çalışmalar esnasında nar ekşisinin 4 farklı dozu $(10,20,40$ ve $80 \mu \mathrm{l}$ plak $^{-1}$ ) yapılan ön denemeler sonucuna göre kullanılmıştır. Tablo 2 incelendiğinde Hatay'dan alınan nar ekşisinin $10 \mu 1$ plak $^{-1}$ ve $20 \mu 1$ plak $^{-1}$ dozlarında; Şanlıurfa'dan alınan nar ekşisinin ise tüm dozlarında TA 98'e karşı antimutajenik özellik tespit edilmiştir. Antimutajenite deneylerinde, antimutajenik aktivitenin belirlenmesi için, pozitif kontrol ve incelenecek olan örneklerin ön denemelerle belirlenen dozları birlikte verilerek revertant koloni sayısının pozitif kontrole göre azalması beklenir. Şanlıurfa nar ekşisinin $S$. Typhimurium TA98 suşu için denenen en yüksek dozunda $\left(80 \mu 1\right.$ plak $\left.^{-1}\right)$ revertant koloni sayısı pozitif kontrole göre oldukça azalmıştır. Ancak Şanlıurfa nar ekşisi örneklerinin denenen tüm dozları arasında bir fark çıkmadığ 1 , hepsinin aynı etkiyi gösterdiği gözlenmiştir. Hatay nar ekşisinde ise uygulanan doz arttıkça antimutajen etkinin azaldığı görülmektedir. Doz ile negatif bir ilişki söz konusudur. Bölgeler arasında karşılaştırma da ise sadece $80 \mu 1$ plak $^{-1}$ denenen en yüksek dozda anlamlı bir fark tespit edilmiştir.

Tablo 2. Hatay ve Şanlıurfa nar ekşilerinin $S$. Typhimurium TA 98 suşu üzerine grup içi ve gruplar arası antimutajenik etkisi

\begin{tabular}{|c|c|c|c|}
\hline \multirow[t]{2}{*}{ Suş } & \multirow[t]{2}{*}{ Test Örneği } & \multirow[t]{2}{*}{$\begin{array}{l}\text { Örnek Miktarı } \\
\left(\mu l \text { plak }^{-1}\right)\end{array}$} & Geriye dönen (revertant) koloni sayısı \\
\hline & & & Ortalama \pm SD $^{* *}$ \\
\hline \multirow[t]{6}{*}{ TA98 } & \multirow[t]{6}{*}{ Hatay nar ekşisi } & Kontrol $^{* * *}$ & $18.67 \pm 3.22^{\mathrm{a}}$ \\
\hline & & $\begin{array}{c}\text { Pozitif kontrol } \\
\text { (4-NPD) }\end{array}$ & $1791.33 \pm 311.54^{\mathrm{b}}$ \\
\hline & & $10 \mu \mathrm{l} \mathrm{\text {plak } ^ { - 1 }}$ & $757.67 \pm 109.25^{\text {cdx }}$ \\
\hline & & $20 \mu 1$ plak $^{-1}$ & $1050.67 \pm 176.57^{\text {cdex }}$ \\
\hline & & $40 \mu \mathrm{l}$ plak $^{-1}$ & $1312.00 \pm 549.39^{\text {abdx }}$ \\
\hline & & $80 \mu 1$ plak $^{-1}$ & $1346.00 \pm 54.37^{\text {bey }}$ \\
\hline \multirow[t]{6}{*}{ TA98 } & \multirow[t]{6}{*}{ Şanlıurfa nar ekşisi } & Kontrol & $18.67 \pm 3.22^{\mathrm{a}}$ \\
\hline & & $\begin{array}{c}\text { Pozitif kontrol }^{*} \\
\text { (4-NPD) }\end{array}$ & $1791.33 \pm 311.54^{\mathrm{b}}$ \\
\hline & & $10 \mu 1$ plak $^{-1}$ & $743.33 \pm 175.29^{\mathrm{cx}}$ \\
\hline & & $20 \mu \mathrm{l}$ plak $^{-1}$ & $694.33 \pm 224.44^{\mathrm{cx}}$ \\
\hline & & $40 \mu \mathrm{l}$ plak $^{-1}$ & $842.00 \pm 121.31^{\mathrm{cx}}$ \\
\hline & & $80 \mu \mathrm{l} \mathrm{\text {plak } ^ { - 1 }}$ & $612.67 \pm 56.90^{\mathrm{cx}}$ \\
\hline
\end{tabular}

4-nitro- $O$-fenilendiamin, ${ }^{* *} \mathrm{SD}:$ Standart sapma, veriler aritmetik ortalama \pm standart sapma şeklinde sunulmuştur. a, b, c, d ve e harfleri ile gösterilen veriler, aynı bölgeden elde edilen nar ekşisinin farklı dozlarının birbirleri ve kontrol ile pozitif kontrol grupları arasındaki istatistiksel ayrımını, x ve y harfleri ile gösterilen veriler aynı nar suyu dozu için bölgeler arasındaki istatistiksel ayrımı göstermektedir, farklı harfler ile gösterilen veriler arasında $P<0.05$ düzeyinde fark vardır $(\mathrm{N}=3),{ }^{* * *}$ Test maddesi ve pozitif kontrol eklenmeden sadece $S$. Typhimurium TA 98 ekimi yapılan gruplar 
TA 100 suşuna karşı da her iki nar ekşisinin 4 farklı konsantrasyonu $(10,20,40$ ve $80 \mu 1$ plak $^{-1}$ ) yapilan ön denemeler sonucuna tespit edilmiştir. Tablo 3'ten de anlaşılabileceği üzere Hatay ve Şanlıurfa'dan alınan nar ekşilerinin ön denemeler sonucunda tespit edilen ve kullanılan hiçbir dozu TA 100'e karşı istatistiksel olarak antimutajenik özellik göstermemiştir. Bunun yanında istatistiksel olarak da bölgeler arasında anlamlı bir fark bulunamamıştır.

Tablo 3. Hatay ve Şanlıurfa nar ekşilerinin $S$. Typhimurium TA 100 suşu üzerine grup içi ve gruplar arası antimutajenik etkisi

\begin{tabular}{|c|c|c|c|}
\hline \multirow[t]{2}{*}{ Suş } & \multirow[t]{2}{*}{ Test Örneği } & \multirow[t]{2}{*}{$\begin{array}{l}\text { Örnek Miktarı } \\
\left(\mu l \text { plak }^{-1}\right)\end{array}$} & Geriye dönen (revertant) koloni sayısı \\
\hline & & & Ortalama $\pm \mathbf{S D}^{* *}$ \\
\hline \multirow[t]{6}{*}{ TA 100} & \multirow[t]{6}{*}{ Hatay nar ekşisi } & Kontrol & $178.67 \pm 9.45$ \\
\hline & & $\begin{array}{l}\text { Pozitif kontrol }^{*} \\
\text { (SA) }\end{array}$ & $2834.67 \pm 1952.75$ \\
\hline & & $10 \mu \mathrm{l}$ plak $^{-1}$ & $4192.67 \pm 107.80$ \\
\hline & & $20 \mu \mathrm{l}$ plak $^{-1}$ & $4388.33 \pm 180.97$ \\
\hline & & $40 \mu \mathrm{l}$ plak $^{-1}$ & $3752.00 \pm 656.38$ \\
\hline & & $80 \mu \mathrm{l} \mathrm{\text {plak } ^ { - 1 }}$ & $3861.33 \pm 735.68$ \\
\hline \multirow[t]{6}{*}{ TA 100} & \multirow[t]{6}{*}{ Şanlıurfa nar ekşisi } & Kontrol & $178.67 \pm 9.45$ \\
\hline & & $\begin{array}{l}\text { Pozitif kontrol }^{*} \\
\text { (SA) }\end{array}$ & $2834.67 \pm 1952.75$ \\
\hline & & $10 \mu \mathrm{l}$ plak $^{-1}$ & $4113.33 \pm 310.64$ \\
\hline & & $20 \mu \mathrm{l}$ plak $^{-1}$ & $4239.33 \pm 643.55$ \\
\hline & & $40 \mu 1$ plak $^{-1}$ & $3915.67 \pm 451.37$ \\
\hline & & $80 \mu \mathrm{l} \mathrm{plak}{ }^{-1}$ & $3912.33 \pm 1108.26$ \\
\hline
\end{tabular}

${ }^{*}$ Sodyum azid, ${ }^{* *}$ SD: Standart sapma, veriler aritmetik ortalama \pm standart sapma şeklinde sunulmuştur, veriler arasında istatistiksel ayrım bulunmamaktadır $(\mathrm{P}>0.05 ; \mathrm{N}=3)$, ${ }^{* * *}$ Test maddesi ve pozitif kontrol eklenmeden sadece $S$. Typhimurium TA 100 ekimi yapılan gruplar

\section{Sonuç ve Tartışma}

Sonuç olarak, nar ekşisinin hem geleneksel olarak üretilen hem de ticari olarak satın alınan formları Türkiye genelinde yemeklerde ve salatalarda lezzet arttırıcı olarak tüketilmektedir. Bu çalışmada ise günlük diyet içerisinde tüketilen nar ekşisinin antibakteriyel ve antimutajenik etkisinin incelenmesi amaciyla, Hatay ve Şanlıurfa'dan temin edilen ve geleneksel olarak üretilen iki faklı nar ekşisi örneği analiz edilmiştir.

Konuyla alakalı yapılan önceki çalışmalarda nar meyvesinde sitrik asidin bol bulunduğu bildirilmiş olup (Saxena vd., 1987), sitrik asidin de antimikrobiyel aktiviteye sahip olduğu bilinmektedir. Davidson and Branen (1993) tarafından yapılan bir çalışmada ise sitrik asidin E. coli, L. monocytogenes, S. Typhimurium, $S$. aureus ve Yersinia enterocolitica üzerinde antimikrobiyel etkiye sahip olduğu belirlenmiştir. Yapılan bir diğer çalışmada parça ve kıyma et örneklerinin nar ekşisi ile muamele edilmeden ve edildikten sonraki mikroorganizma yükü incelenmiş ve tespit edilen mikroorganizma sayının nar ekşisi ile muamele edilenlerde azaldığı tespit edilmiştir (Yapar, 2006). Yapılan benzer bir çalışmada ise nar ekşisinin E. coli $\mathrm{O} 157$ ve $L$. monocytogenes'e karşı inhibe edici etkiye 
sahip olduğu tespit edilmiştir (Kunduhoğlu ve Pilatin, 2009). Karabıyıklı (2010) tarafından yapılan bir çalışmada, nar ekşisi örneklerinin marul, taze soğan, maydanoz ve dereotunun mikrobiyel yüklerinde azalamaya neden olduğu belirlenmiştir. Diğer bir çalışmada ise ticari olarak üretilen nar ekşisi soslarının ve geleneksel olarak üretilen nar ekşilerinin S. aureus (ATCC 25923) ve $E$. coli O157 : H7 (ATCC 43895) üzerinde inhibitör etkiye neden olduğu, ancak geleneksel nar ekşisi örneklerinin ticari nar ekşisi soslarına oranla daha güçlü bir etkiye sahip olduğu bildirilmiştir (Kışla ve Karabıyıklı, 2013). Yapılan çalışmalardan elde edilen ortak kaniya dayanarak, nar ekşisinin antimikrobiyel etkiye sahip olduğu anlaşılmaktadır. Bu çalışmadan elde edilen antibakteriyel aktivite sonuçları da bu durumu destekler nitelikte olup, kullanılan test bakterilerine karşı değişen oranlarda antibakteriyel aktivite tespit edilmiştir. Ancak; sonuçlar incelendiğinde Hatay nar ekşisinin Şanlıurfa nar ekşisine oranla daha yüksek bir antibakteriyel aktivite sergilediği görülmektedir. Bitkilerin içerikleri yetiştikleri toprak yapısına, iklimsel koşullara, bitkinin güneş 1şı̆̆ından yararlanma süresi ve miktarına, hasat zamanına, hasat sonrasındaki depolanma koşullarına, kültürel uygulamalara vb. durumlara göre değişiklik gösterebilmekte (Heimler vd., 2006) olup bu durum ise çalışma sonuçlarını etkileyebilmektedir. Ayrıca; geleneksel nar ekşisinin yapımı aşamasındaki ufak farklılıklar ve/veya nar ekşisinin kıvamındaki faklılıklar da sonuçlar arasındaki farkı etkileyebilmektedir.

Nar ekşisi dışında nar suyunun antimikrobiyel aktivitesi ile alakalı çalışmalar incelendiğinde ise nar suyunun $S$. aureus, E. coli ve $P$. aeruginosa'ya karş1 sırasıyla $11,8.5$ ve $10.5 \mathrm{~mm}$ çapında inhibisyon zonu oluşturduğu bildirilmiştir (Hama vd., 2014). Ar1 ve Erbil (2018) tarafindan yapılan bir çalışmada ise ticari olarak satın alınan nar suyunun bazı test bakterileri üzerinde yüksek oranda antibakteriyel etkiye sahip olduğu tespit edilmiştir.

Yapılan çalışmalara genel olarak bakıldığında, nar ekşisi ve diğer nar ürünlerinin antimikrobiyel aktiviteye sahip olduğu bildirilmiş olup, bu çalışmadan elde edilen antibakteriyel aktivite sonuçları ile uyum göstermektedir.

Çeşitli faktörlere bağlı olarak meydana gelen gen mutasyonları insan sağlığını çeşitli yönden olumsuz etkilemekte ve birçok hastalık için tetikleyici vazife görmektedir. Bundan dolayıdır ki doğal ürünlerde tespit edilen antimutajenik aktivite oldukça önemlidir. Konuyla alakalı çalışmalardan birinde nar kabuğunun etil asetat, aseton, metanol ve sulu ekstraktları kullanılmış olup, TA 100 ve TA 1535 suşlarına karşı antimutajen aktivite çalışılmıştır. Elde edilen sonuçlar neticesinde başta nar kabuğunun sulu ekstraktı olmak üzere tüm ekstraktların $2500 \mu \mathrm{g}$ plak $^{-1}$ dozunda antimutajenik aktivite gözlenmiştir (Negi vd., 2003). Benzer bir diğer çalışmada da narın iki farklı İran çeşidine ait kabuk ekstraktları TA 100 ve TA 1535' e karş1 antimutajenik aktivite bakımından çalışılmış ve sonuçlar göstermiştir ki her iki nar kabuğu ekstraktı da antimutajenik aktivite sergilemiştir (Ghasemian vd., 2006). Yapılan bazı çalışmalarda bitkilerin içerdiği polifenollerin antimutajenik ve antikarsinojenik ajan olarak görev alabildiği bildirilmiştir (Ayrton vd., 1992; Bu-Abbas vd., 1994). Bundan dolayıdır ki narın sahip olduğu antimutajenik özelliğin içerdiği polifenollerden

kaynaklanabileceği düşünülmektedir.

$\mathrm{Bu}$ çalışmada elde edilen sonuçlar, iki farklı yöreye ait nar ekşisi örneklerinin test edilen bakterilere karşı belirli seviyede antibakteriyel ve $S$. Typhimurium TA 98'e karş1 denenen dozlarının ise antimutajenik aktivite sergilediğini ortaya koymuştur. Bu sonuçlar 
antibiyotik dirençliliğinin oldukça arttığı son günlerde oldukça önem arz etmekte olup, nar ekşisinin sergilediği antimutajen özellikten dolayı da ayrıca bir önem taşımaktadır. Ayrıca; insan sağlığını destekler nitelikteki bu sonuçlar, konuyla alakalı yapılacak olan benzer çalışmalara da referans oluşturacaktır.

\section{Kaynaklar}

Arı, M, Erbil, N. 2018. "Ticari Olarak Satın Alınan Nar Suyunun Antibakteriyal ve Bazı Antibiyotiklerle Sinerjistik Etkisi”, I Ig dir Üniversitesi Fen Bilimleri Enstitüsü Dergisi, 8(3), 131-135.

Ayrton, A. D., Lewis, D. F. V., Walker, R., Ioannides, C. 1992. "Antimutagenicity of ellagic acid towards the food mutagen IQ: investigation into possible mechanism of action", Food and Chemical Toxicology, 30, 289-295.

Bu-Abbas, A., Clifford, M. N., Walker, R., Ioannides, C. 1994. "Marked antimutagenic potential of aqueous gren tea extracts: mechanism of action", Mutagenesis, 9(4), 325-331.

Davidson, M. P., Branen, A.L. (1993). "Antimicrobials in Food 2nd. Ed", pp. 647, New York.

Ghasemian, A., Mehrabian, S., Majd, A. 2006. "Peel Extracts of Two Iranian Cultivars of Pomegranate (Punica granatum) have Antioxidant and Antimutagenic Activities", Pakistan Journal of Biological Sciences, 9(7), 1402-1405.

Gündoğdu, M., Yılmaz, H. 2013. "Bazı Standart Nar (Punica granatum L.) Çeşitleri ve Genotiplerine Ait Meyvelerin C Vitamini, Şeker ve Besin Elementleri İçeriklerinin Belirlenmesi”, Yüzüncü Yll Üniversitesi Tarım Bilimleri Dergisi, 23(3), 242-248.

Hama, A. A., Taha, Y., Qadir, S. A. 2014. "The antimicrobial activity of pomegranate (Punica granatum) juice", International Journal of Scientific \& Engineering Research, 5(10), 796-798.
Heimler, D., Vignolini, P., Dini, M.G., Vincieri, F.F., Pomani, A. 2006. “Antiradical activity and polyphenol composition of local Brassicaiceae adible varieties", Food Chemistry, 99, 464-469.

Ikken, Y., Cambero, I., Marin, M. L., Martinez, A., Haza, A. I., Morales, P. 1998. "Antimutagenic effect of fruit and vegetable aqueous extracts against $N$-nitrosamines evaluated by the Ames test", Journal of Agricultural and Food Chemistry, 46(12), 5194-5200.

Karabıyıklı, Ş. 2010. "Bazı Nar Ürünlerinin Antimikrobiyal Etkilerinin Belirlenmesi ve Salatalarda Koruyucu Etkisinin Araştırılması", Doktora Tezi, Ege Üniversitesi Fen Bilimleri Enstitüsü Gıda Mühendisliği Anabilim Dal, İzmir.

Kışla, D., Karabıyıklı, Ş. 2013. "Antimicrobial Effect of Sour Pomegranate Sauce on Escherichia coli O157 : H7 and Staphylococcus aureus", Journal of Food Science, 78(5), M715-M718.

Kunduhoğlu, B., Pilatin, S. 2009. "Nar ekşisi ve sumak ekșisi'nin Escherichia coli $\mathrm{O} 157$ ve Listeria monocytogenes üzerine antimikrobiyal etkisinin belirlenmesi", Geleneksel Gidalar Sempozyumu, 27-29 Mayıs, Van.

Lee, J., Watson, R. R. 1998. "Pomegranate: A role in health promotion and AIDS", Nutrition Food and AIDS, CRC Press, Boca Raton, Florida, USA: Ed. Watson RR, 179192.

Malik, A., Afaq, F., Sarfaraz, S., Adhami, V. M., Syed, D. N., Mukhtar, H. 2005. "Pomegranate Fruit Juice for Chemopreventive and Chemotherapy of Prostate Cancer", PNAS, 102(41), 1481314818.

Maron, D., Ames, B. 1983. "Revised Methods for the Salmonella Mutagenicity Test”, Mutation Res, 113, 173-215.

Melgarejo, P., Salazar, D. M., Artes, F. 2000. "Organic Acids and Sugars Composition of Harvested Pomegranate Fruits", European 
Food Research and Technology, 211(3), 185190.

Negi, P. S., Jayaprakasha, G. K., Jena, B. S. 2003. "Antioxidant and antimutagenic activities of pomegranate peel extracts", Food Chemistry, 80, 393-397.

Özkal, N., Dinç, S. 1993. "Punica granatum L. (Nar) Bitkisinin Kimyasal Bileşimi ve Biyolojik Aktiviteleri”, Ankara Eczacılık Fakültesi Dergisi, 22, 1-2.

Rahimi, H. R., Arastoo, M., Ostad, S. N. 2012. "A Comprehensive Review of Punica granatum (Pomegranate) Properties in Toxicological, Pharmacological, Cellular and Molecular Biology Researches", Iranian Journal of Pharmaceutical Research, 11(2), 385-400.

Rauha, J. P., Remes, S., Heinonen, M., Hopia, A., Kahkonen, M., Kujala, T., Pihlaja, K., Vuorela, P. 2000. "Antimicrobial Effects of Finnish Plant Extracts Containing Flavonoids and Other Phenolic Compounds", International Journal of Food Microbiology, 56, 3-12.

Saxena, A. K., Mana, J. K., Berry, S. K. 1987. "Pomegranates: post-harvest technology, chemistry and processing", Indian Food Packer, 41, 43-60.

Turgut, D. Y., Seydim, A. C. 2013. "Akdeniz Bölgesi'nde Yetiştirilen Bazı Nar (Punica granatum L.) Çeşit ve Genotiplerinin Organik Asit ve Şeker Kompozisyonu", Akademik Ziraat Dergisi, 2(1), 35-42.

Ünal, Ç., Velioğlu, S., Cemeroğlu, B. 1995. “Türk Nar Sularının Bileşim Öğeleri”, Glda, 20(6), 339-345.

Yapar, F. 2006. "Parça Et ve Kıymalarda Erik Ekşisi, Nar Ekşisi ve Limon Tuzunun Antibakterial Etkisi”, Yüksek Lisans Tezi, Çukurova Üniversitesi Fen Bilimleri Enstitüsü Gıda Mühendisliği Anabilim Dalı, Adana. 